\title{
Solar Radiation Effects on Dry Matter Accumulations and Transfer in Maize
}

\author{
Yunshan Yang ${ }^{1,2}$, Xiaoxia Guo ${ }^{2}$, Guangzhou Liu ${ }^{1}$, Wanmao Liu' ${ }^{2}$, Jun Xue ${ }^{1}$, Bo Ming ${ }^{1}$, \\ Ruizhi Xie ${ }^{1}$, Keru Wang ${ }^{1}$, Peng Hou ${ }^{1 *}$ and Shaokun $\mathrm{Li}^{1,2 *}$ \\ 1 Key Laboratory of Crop Physiology and Ecology, Ministry of Agriculture and Rural Affairs/Institute of Crop Sciences, Chinese \\ Academy of Agricultural Sciences, Beijing, China, ${ }^{2}$ The Key Laboratory of Oasis Eco-Agriculture, Xinjiang Production and \\ Construction Corps/College of Agronomy, Shihezi University, Shihezi, China
}

OPEN ACCESS

Edited by:

loannis Tokatlidis,

Democritus University of

Thrace, Greece

Reviewed by:

Baizhao Ren,

Shandong Agricultural

University, China

Xiancan Zhu,

Anhui Normal University, China

*Correspondence:

Peng Hou

houpeng@caas.cn

Shaokun L

lishaokun@caas.cn

Specialty section:

This article was submitted to

Crop and Product Physiology,

a section of the journal

Frontiers in Plant Science

Received: 18 June 2021

Accepted: 16 August 2021 Published: 16 September 2021

Citation:

Yang Y, Guo X, Liu G, Liu W, Xue J, Ming $B$, Xie R, Wang K, Hou P and Li S (2021) Solar Radiation Effects on

Dry Matter Accumulations and Transfer in Maize.

Front. Plant Sci. 12:727134.

doi: 10.3389/fp/s.2021.727134
Solar radiation is the energy source for crop growth, as well as for the processes of accumulation, distribution, and transfer of photosynthetic products that determine maize yield. Therefore, learning the effects of different solar radiation amounts on maize growth is especially important. The present study focused on the quantitative relationships between solar radiation amounts and dry matter accumulations and transfers in maize. Over two continuous years (2017 and 2018) of field experiments, maize hybrids XY335 and ZD958 were grown at densities of $4.5 \times 10^{4}$ (D1), $7.5 \times 10^{4}$ (D2), $9 \times 10^{4}$ (D3), $10.5 \times 10^{4}$ (D4), and $12 \times 10^{4}$ (D5) plants/ha at Qitai Farm (89 $\left.34^{\prime} \mathrm{E}, 44^{\circ} 12^{\prime} \mathrm{N}\right)$, Xinjiang, China. Shading levels were 15\% (S1), 30\% (S2), and 50\% (S3) of natural light and no shading (CK). The results showed that the yields of the commonly planted cultivars XY335 and ZD958 at S1, S2, and S3 (increasing shade treatments) were 7.3, 21.2, and $57.6 \%$ and $11.7,31.0$, and $61.8 \%$ lower than the control yields, respectively. Also, vegetative organ dry matter translocation (DMT) and its contribution to grain increased as shading levels increased under different densities. The dry matter assimilation amount after silking (AADMAS) increased as solar radiation and planting density increased. When solar radiation was $<580.9$ and $663.6 \mathrm{MJ} / \mathrm{m}^{2}$, for XY335 and ZD958, respectively, the increase in the AADMAS was primarily related to solar radiation amounts; and when solar radiation was higher than those amounts for those hybrids, an increase in the AADMAS was primarily related to planting density. Photosynthate accumulation is a key determinant of maize yield, and the contributions of the vegetative organs to the grain did not compensate for the reduced yield caused by insufficient light. Between the two cultivars, XY335 showed a better resistance to weak light than ZD958 did. To help guarantee a high maize yield under weak light conditions, it is imperative to select cultivars that have great stay-green and photosynthetic efficiency characteristics.

Keywords: maize, solar radiation, density, dry matter accumulation and translocation, photosynthates, leaf area duration 


\section{INTRODUCTION}

Food shortage has long been a worldwide problem (Jia et al., 2011), but the recent COVID-19 pandemic, beginning in early 2020 , has not only seriously affected public health but has also added significant uncertainty to national and global food supplies (Balwinder et al., 2020; Lamichhane and Reay-Jones, 2021). One of the most important crops globally, maize, provides food and protein for people, as well as raw material for industrial production (Gao et al., 2017). However, maize production is vulnerable to abnormal weather conditions, such as continuous rain, wet weather, and low-light levels caused by cloud cover, and that has been exacerbated due to worldwide climate change and environmental pollution (Wu et al., 2020). Solar radiation drives crop photosynthesis and yields, as well as the formation and development of plant organs (Ding et al., 2005; Zhang et al., 2007; Dordas, 2009; Ye et al., 2020). Studies have shown that global solar radiation has been decreasing by an average of 1.4$2.7 \%$ per decade, and the effective sunlight duration decreasing by $1.28 \%$ each decade over a period of time in China (Cui et al., 2015; Ren et al., 2016). For example, in the Huang-Huai Plain region, predicted maize yields could be reduced by $3-6 \%$ by rainy weather and insufficient light during the growing period, especially given the background of global climate change (Cui et al., 2012; Ren et al., 2016; Gao et al., 2017). Therefore, exactly how solar radiation changes affect maize production must be investigated to help guarantee maize yield under future climate change scenarios.

Dry matter production, accumulation, and transportation are important factors that determine maize yield (Hou et al., 2020; Liu et al., 2020a,b), which is significantly correlated with the continuous increase of dry matter accumulation after flowering (Zhang et al., 2016). Gao et al. (2017) suggested that $\sim 60 \%$ of the carbohydrates in maize grains come from post-flower photosynthetic products, whereas Yan et al. (2001) suggested that higher yielding cultivars have stronger postflowering photosynthetic capacity but poor assimilate transfer to grain. Nevertheless, some studies posited that the main reason for higher maize yields is the accumulation of more dry matter at the pre-silking stage and a higher transport rate in the post-silking stage (Yang et al., 1999). Barnabás et al. (2007) demonstrated that maize grain yield is dependent on post-silking photosynthate accumulation, but the translocation of reserved carbohydrates in vegetative organs to grains cannot be ignored ( $\mathrm{Mu}$ et al., 2010; Wang et al., 2020a; Ye et al., 2020). Maize yield may effectively be increased by increasing dry matter production capacity and then transferring as much of that accumulated dry matter to the grain as possible (Chen, 1994; Ding et al., 2005; Hou et al., 2012). Although aboveground dry matter accumulation, partitioning, and translocation have been well documented in rice (Yang et al., 1997), wheat (Dordas, 2009; Zhou et al., 2012), cotton (Ibrahim et al., 2010), and maize (Zhu et al., 2011; Pu et al., 2016), little is known about the effects of solar radiation on dry matter accumulation and translocation in maize.

Field shading, a common method used to study the effects of solar radiation on crop growth (Yang et al., 2001; Cui et al., 2015; Ren et al., 2016; Fan et al., 2018), shows how different shading periods have different effects on maize growth (Zhang et al., 2006; Cui et al., 2013a; Shi et al., 2015; Gao et al., 2017). Shading during the reproductive period of the maize decreases grain yield more than during the vegetative growth stages (Early et al., 1967; Zhang et al., 2007; Yang et al., 2019). Furthermore, different degrees of shading have different effects on maize growth and development (Cui et al., 2013a). The accumulation and distribution of dry matter in the stem, leaf, and sheath are important factors in maize grain yield (Karlen et al., 1987; Gao et al., 2017; Yang et al., 2021). Also, assimilates in the vegetative organs gradually move to the grain in the late growth stage (Yang et al., 1997; Ma et al., 2008; Gao et al., 2017). Modern maize grain yield improvements are highly dependent on increasing plant density while enabling the plants to intercept more solar radiation (Liu et al., 2017, 2021c; Hou et al., 2020), and planting density affects light quality and other environmental factors that influence the yield as well (Jin et al., 2020). Also, planting density has important effects on maize dry matter partitioning between vegetative and reproductive organs (Wei et al., 2019), as planting density increases, the numbers of vegetative organs increase while that of reproductive organs decrease (Liu et al., 2011). Previous studies have indicated that leaf area index (LAI) increases as plant density increases (Xu et al., 2017; Liu et al., 2020a), an overly high LAI may cause self-shading and has been noted for possible photosynthetic decrease and yield loss (Cui et al., 2013b; Liu et al., 2015, 2020a; Srinivasan et al., 2017), and the increase of leaf area duration (LAD) of maize was accompanied by the increase of photosynthetic rate, and finally significantly increased the total biomass (Liu et al., 2020a).

There have been many studies on shading (Andrade et al., 1993; Andrade and Ferreiro, 1996; Cerrudo et al., 2013), however, little is known about the interactive and quantitative relationships between solar radiation, planting density, and hybrids in maize. Additionally, because most of the previous studies were conducted in lower solar radiation areas in China (Jia et al., 2007; Cui et al., 2015; Ren et al., 2016), their findings were not closely connected to the actual production conditions after shading. In this study, we chose a farm in the Xinjiang region, the area with the most abundant solar radiation in China (Xue et al., 2016), and the two most widely planted maize genotypes were selected. We also established different shading and planting density treatments to re-create different solar radiation conditions so that we could study the quantitative relationships between maize dry matter accumulations and transfers and solar radiation. Our results provide a theoretical basis for cultivar breeding and improved field management as agronomists cope with climate change and dense planting.

\section{MATERIALS AND METHODS \\ Experimental Design}

We conducted field experiments in 2017 and 2018 at the Qitai Farm $\left(43^{\circ} 49^{\prime} 27^{\prime \prime} \mathrm{N}, 89^{\circ} 48^{\prime} 22^{\prime \prime} \mathrm{E}\right)$ in Xinjiang, China. A split block design was conducted with cultivars as the main factor, planting density as the subplot factor, and shading level as the secondary subplot factor, and all plots were arranged in a completely randomized design with three replications. We used maize 
hybrids Xianyu 335 (XY335) and Zhengdan 958 (ZD958) in both the years because they are widely grown in China, and the plant architecture of these two hybrids was different, such as leaf length and leaf angles (Ma et al., 2014; Hou et al., 2020). The experimental plots measured $11 \times 10 \mathrm{~m}$ and adjacent plots were separated by a $1 \mathrm{~m}$ wide walkway. Different environmental solar radiation conditions were created by manipulating shading and planting density. The maize was planted at five different densities: $4.5 \times 10^{4}(\mathrm{D} 1), 7.5 \times 10^{4}(\mathrm{D} 2), 9 \times 10^{4}(\mathrm{D} 3), 10.5 \times 10^{4}$ (D4), and $12 \times 10^{4}$ (D5) plants/ha in 2018 and three planting densities (D2, D4, and D5) in 2017. Shading levels were 50 (S3), 30 (S2), and 15\% (S1) of natural light and no shading (CK). We used nylon nets to build temporary shading sheds. The nets were $4.5 \mathrm{~m}$ above the ground, which were fixed in place $\sim 1.5 \mathrm{~m}$ above the maize canopy in order to maintain the same microclimatic conditions except for solar radiation as in the unshaded portions of the field. The shading period began at silking and lasted until maturity. Shading nets were designed and fabricated to have different shading strengths, and the incident light quality in the maize canopy was not affected by field shading (Andrade et al., 2000; Jia et al., 2011; Yang et al., 2020).

All experimental plots were irrigated $(15 \mathrm{~mm})$ on the $1 \mathrm{st}$ day after sowing, and starting from 60 days after sowing, single water applications of $58 \mathrm{~mm}$ were delivered at 9-10 day intervals throughout the growing season for a total of nine applications. The total irrigation amount was $\sim 540 \mathrm{~mm}$ (Zhang et al., 2017). All weeds, diseases, and pests were controlled. Base fertilizers were applied before sowing and included 150 $\mathrm{kg} / \mathrm{ha} \mathrm{N}$ from urea, $225 \mathrm{~kg} / \mathrm{ha} \mathrm{P}_{2} \mathrm{O}_{5}$ (super phosphate), and $75 \mathrm{~kg} / \mathrm{ha} \mathrm{K}_{2} \mathrm{O}$ (from potassium sulfate). To ensure a nonlimiting supply of nutrients, additional urea $(300 \mathrm{~kg} / \mathrm{ha} \mathrm{N})$ was applied via drip irrigation in alternate irrigations during the growing season.

\section{Sampling and Measurement}

In each plot, three adjacent plants from the same inside row were cut manually at silking and at physiological maturity. We assigned plant part categories as stalk (stalk, sheath, and tassel), leaf, cob, husk, and grain; and after harvest, the parts were oven dried $\left(85^{\circ} \mathrm{C}\right)$ to a constant weight. At physiological maturity, a $3.3 \times 5 \mathrm{~m}$ area [in an alternating narrow-wide $(40: 70 \mathrm{~cm})$ row planting pattern] was manually harvested from the center of each plot and its grain weight was measured (Liu et al., 2020a). We determined grain moisture content using a PM8188 portable moisture meter (Kett Electric Laboratory, Tokyo, Japan), and grain yield and thousand kernel weights (TKW) were determined at $14 \%$ moisture content. The kernel rows per ear and kernel number per row were calculated using 10 selected ears. The kernel number per ear (KNP) was calculated as follows: KNP = kernel rows per ear $\times$ kernel number per row (Liu et al., 2019). In 2018, every 10 days after silking and until maturity, leaf area measurements [leaf length (L) and maximum leaf width (W) of all the leaves on each tagged plant) were taken from five marked, representative plants from each plot. Then leaf areas and LAIs were calculated as described by Xu et al. (2017).

$$
\text { LAI }=\frac{\begin{array}{r}
\text { Leaf area }=\mathrm{L} \times \mathrm{W} \times 0.75 \\
\text { Leaf area per plant } \times \text { plant number per plot }
\end{array}}{\text { Plot area }}
$$

Leaf area duration (LAD) was calculated as:

$$
L A D=\frac{L 1+L 2}{2} \times(t 1-t 2)
$$

where L1 and L2 are the leaf area per plant at time $t 1$ (maturity) and $t 2$ (silking), respectively (Liu et al., 2021a).

We obtained meteorological data for the 2017 and 2018 maize growing seasons from a WatchDog 2000 Weather Station data logger (Spectrum Technologies, Inc., Washington, DC, United States) located in the experimental field (the data were recorded at hourly intervals), and the measured PAR was averaged in the wide and narrow rows at the top and the bottom of the canopies at 13:00 and 15:00 hours (Xu et al., 2017) on clear days using a SunScan (Delta-T Devices, Cambridge, United Kingdom). The total intercepted PAR was calculated according to the following formula.

$$
\text { Total intercepted PAR }(\mathrm{MJ} / \mathrm{m} 2)=\left(1-\frac{B}{A}\right) \times C \text {, }
$$

where $A$ is PAR above the canopy, $B$ is the transmitted PAR at the bottom of the canopy, and $C$ is total accumulated par from silking to maturity.

In 2018, ear leaves per plot were chosen for photosynthesis measurement during the grain filling stage (20 days after silking). First, gas exchange measures were made on clear days at 13:00 and 15:00 using an LI-6400 programmable, portable open-flow gas exchange system (Li-Cor Inc., Lincoln, NE, United States). We performed light induction by keeping the leaves in the leaf chamber with the $\mathrm{CO}_{2}$ concentration controlled at $400 \mu \mathrm{mol}$ $\mathrm{CO}_{2}$ (per mol air) and under $\mathrm{PAR}=2,000 \mu \mathrm{mol} / \mathrm{m}^{2} / \mathrm{s}$ until the parameter readings were stable (Liu et al., 2020a). Dry matter translocation (DMT) of vegetative organs (stalk + leaf), contribution of pre-silking dry matter to grain (CDMG), and the amount of assimilated dry matter after silking (AADMAS) were calculated as described by Zhu et al. (2011) and all weights were measured as $t /$ ha.

$$
\begin{array}{r}
\text { DMT of vegetative organs }=\text { Dry matter weight at silking } \\
- \text { Dry matter weight at maturity (5) } \\
\text { CDMG of the vegetative organ (\%) } \\
=\frac{\text { DMT of the vegetative organ }}{\text { Kernel dry matter weight at maturity }} \times 100(6) \\
\text { AADMAS }=\text { Dry matter weight of grain at maturity } \\
- \text { DMT of vegetative organs (7) }
\end{array}
$$

\section{Statistical Analysis}

Statistical calculations were performed and charts generated in Excel 2016 (Microsoft, Redmond, WA, United States) and Origin 
2018 (OriginLab, Northampton, MA, United States). SPSS ver. 21.0 (IBM SPSS, Chicago, IL, United States) was used to conduct one-way ANOVA followed by Duncan's multiple range tests at $P<0.05$ to test the differences between different treatments in the two study years. Treatment effects and interaction between treatments were analyzed by ANOVA using mixed models. Residuals were analyzed to corroborate the assumptions of the ANOVA. For all of the dependent variables analyzed, year, cultivar, density, and shading level were considered as fixed factors.

\section{RESULTS}

\section{Different Shading Levels Affect Maize Yield, Yield Components, and Dry Weight of Organs Under Different Density Conditions}

Shading affected maize yield, the decrease rate of yield was in the order S3 > S2 > S1, compared with CK (Table 1). Over the 2 years of the experimental period, the mean yields of five planting densities of XY335 were >ZD958; and compared with CK, yields of XY335 decreased $<$ ZD958 after shading. Averaging all planting densities (D1, D2, D3, D4, and D5), and over both the study years, the yields of XY335 and ZD958 at S1, S2, and S3 were $7.3,21.2$, and $57.6 \%$, and $11.7,31.0$, and $61.8 \%$ lower than CK, respectively. Also, the dry matter weight of vegetative organs at maturity were $8.7,8.9$, and $18.2 \%$, and $4.5,10.7$, and $20.2 \%$ lower than CK, respectively (Table 1). Averaging all shading treatments, the yields of XY335 and ZD958 at D1, D2, D3, D4, and D5 were $21.9,21.1,30.0,31.6$, and $35.1 \%$ and $13.3,18.2,42.8,40.4$, and $39.9 \%$, the vegetative organ dry matter weights were 18.6 , $17.0,17.8,21.6$, and $12.8 \%$ and $16.2,13.4,16.3,14.0$, and $8.2 \%$ lower than CK, respectively. The reduction of ear density, KNP, and TKW significantly increased with the increase of shade level (Table 2). The main effect of shading treatment on maize yield components was the decrease in KNP and TKW and therefore the shading mainly affected grain formation and filling after silking. For the cultivars, the KNP and TKW of XY335 were higher than that of ZD958.

\section{Effects of Different Shading Levels on DMT of Vegetative Organs and CDMG Under Different Density Conditions}

Both vegetative organ DMT and pre-silking CDMG increased as shading level increased under different densities (Figure 1). These results showed that over the 2 years and five planting densities, the mean DMTs in CK, S1, S2, and S3 were 0.68, 1.07, 1.91, and $2.01 t /$ ha, while the mean CDMGs were 3.52, 5.54, 11.28 , and $41.25 \%$ ( $15.4 \%$ total), respectively. Shading increased DMT by averages of $56.5,179.4$, and $196.1 \%$, and increased CDMG by averages of $0.6,2.23$, and $10.45 \%$ in S1, S2, and $\mathrm{S} 3$, respectively, compared with those measures in CK. We also showed that the 2-year DMT and CDMG averages of all shading treatments (CK, S1, S2, and S3) for D1, D2, D3, D4, and D5 were $0.16,0.91,2.52,2.04$, and $1.47 t$ tha and 1.92, 9.83, 20.52, 20.21, and 20.33\%, respectively. DMT and CDMG rates increased more for XY335 than for ZD958, thus indicating that XY335 transferred more photosynthetic products to grain than ZD958 under low-solar radiation stress. The XY335 and ZD958 DMTs in CK were 0.40 and $0.97 t /$ ha, respectively, but those measures increased significantly in S1, S2, and S3: by 123.9, 304.8, and $458.4 \%$ for XY335 and by $28.6,127.6$, and $215.9 \%$ for ZD958. Although DMTs increased with the increase of shade levels, the amplitude of the changes between them was not proportional. Likewise, the mean CDMG over both years and all planting densities of XY335 and of ZD958 under S1, S2, and S3 increased significantly (by 121.7, 354.2, and $1549.8 \%$ for XY335 and by 31.7 , 162.9 , and $813.9 \%$ for ZD958) compared with those measures for CK (2.11 and 4.63\% for XY335 and ZD958, respectively).

\section{Quantitative Relationships Between AADMAS and Planting Densities Under Different Solar Radiation Levels}

As solar radiation increased so did AADMAS, which also decreased as planting density increased when solar radiation was low, but increased at the same planting densities when radiation was high (Figures 2A,B). For three-dimensional analysis, we used multiple linear regression to evaluate the interaction effects between planting density and solar radiation on AADMAS in XY335 and ZD958. Combined planting density and solar radiation explained $93 \%$ and $88 \%$ of the variations in AADMAS for XY335 and ZD958, respectively. When the solar radiation was $<580.9$ and $663.6 \mathrm{MJ} / \mathrm{m}^{2}$, for XY335 and ZD958, respectively, increases in AADMAS were primarily related to the amount of solar radiation. When the solar radiation was higher than 580.9 and $663.6 \mathrm{MJ} / \mathrm{m}^{2}$ for XY335 and ZD958, respectively, increases in AADMAS were primarily related to planting density. The XY335 and ZD958 AADMAS of CK were 19.7 and 19.2 t/ha, respectively. AADMAS decreased significantly in S1, S2, and S3 by $8.7,22.7$, and $80.3 \%$ for XY335 and by $7.8,27.3$, and $81.8 \%$ for ZD958. Averaging all shading leves and over both the study years, the AADMAS of XY335 and ZD958 D1, D2, D3, D4, and D5 were 26.0, 32.5, 36.6, 39.8, and $45.2 \%$, and $26.6,32.8,35.4,46.9$, and $45.1 \%$ lower than CK, respectively. The fluctuations of AADMAS and shading level were not synchronous, and which also increased as planting density increased.

\section{Influences of Shading on Photosynthetic Characteristics and LAD of Different Maize Cultivars}

All ear leaf photosynthetic rates $(P n)$ changed significantly after shading (Figure 3) and they decreased as shading levels and planting densities increased $(P n$ of ZD958 was not decreased with increase in plant densities). As shown in Figure 3, Pns were greater for XY335 than for ZD958, as the Pn under S1, S2, and S3 decreased significantly by $18.6,19.54$, and $28.1 \%$, for XY335 and by $31.11,32$, and $33.82 \%$ for ZD958. This indicated that the net leaf $P n$ decreased as shading increased, and since the ratio of the decrease of XY335 was lower than that of 
TABLE 1 | Effects of different shading levels (CK, natural light; S1, 15\% natural light; S2, 30\% natural light; S3, 50\% natural light) and planting densities (D1, $4.5 \times 10^{4}$ plants ha ${ }^{-1}$; D2, $7.5 \times 10^{4}$ plants ha ${ }^{-1}$; D3, $9 \times 10^{4}$ plants ha $^{-1}$; D4: $10.5 \times 10^{4}$ plants ha ${ }^{-1}$; D5, $12 \times 10^{4}$ plants ha $^{-1}$ ) on maize grain yields and dry weights of plant organs (dry matter of vegetative organs at silking [VS] and at maturity [VM]) in 2017 (Y1) and 2018 (Y2).

\begin{tabular}{|c|c|c|c|c|c|c|}
\hline Treatment & \multicolumn{3}{|c|}{ XY335 } & \multicolumn{3}{|c|}{ ZD958 } \\
\hline Y1D2S1 & $18.55 a$ & $11.3 a$ & $12.3 a$ & $16.92 \mathrm{a}$ & $10.3 a$ & $11.2 \mathrm{a}$ \\
\hline Y1D2S2 & $17.02 \mathrm{a}$ & $11.3 \mathrm{a}$ & $13.7 \mathrm{a}$ & $13.90 \mathrm{~b}$ & $10.3 a$ & $11.2 \mathrm{a}$ \\
\hline Y1D2S3 & $12.42 \mathrm{~b}$ & $11.3 a$ & $11.9 a$ & $8.77 \mathrm{c}$ & $10.3 a$ & $9.3 \mathrm{~b}$ \\
\hline Y1D4S1 & $18.16 \mathrm{ab}$ & $14.8 \mathrm{a}$ & $13.5 b$ & $16.66 \mathrm{ab}$ & $14.7 \mathrm{a}$ & $13.5 \mathrm{a}$ \\
\hline Y1D4S2 & $16.20 \mathrm{~b}$ & $14.8 \mathrm{a}$ & $13.7 \mathrm{~b}$ & $13.87 \mathrm{~b}$ & $14.7 \mathrm{a}$ & $13.1 \mathrm{a}$ \\
\hline Y1D4S3 & $11.13 c$ & $14.8 \mathrm{a}$ & $13.9 \mathrm{~b}$ & $8.46 \mathrm{c}$ & $14.7 \mathrm{a}$ & $11.0 \mathrm{~b}$ \\
\hline Y1D5CK & $21.76 \mathrm{a}$ & $16.3 a$ & $16.4 \mathrm{a}$ & $20.13 a$ & $15.1 \mathrm{a}$ & $16.1 \mathrm{a}$ \\
\hline Y1D5S1 & $19.93 a b$ & $16.3 a$ & $15 b$ & $17.34 \mathrm{~b}$ & $15.1 \mathrm{a}$ & $15.3 \mathrm{a}$ \\
\hline Y1D5S2 & $16.99 \mathrm{~b}$ & $16.3 a$ & $13.3 \mathrm{c}$ & $14.14 \mathrm{C}$ & $15.1 \mathrm{a}$ & $15.0 \mathrm{a}$ \\
\hline Y2D1S2 & $17.13 a$ & $7.9 a$ & $9.6 \mathrm{ab}$ & $15.20 \mathrm{a}$ & $7.5 \mathrm{a}$ & $8.6 \mathrm{a}$ \\
\hline Y2D1S3 & 8.84 b & $7.9 a$ & $7.9 \mathrm{~b}$ & $8.01 \mathrm{~b}$ & $7.5 \mathrm{a}$ & $7.1 \mathrm{~b}$ \\
\hline Y2D2CK & $19.29 a$ & $12.0 \mathrm{a}$ & $11.3 \mathrm{a}$ & $17.61 \mathrm{a}$ & $11.6 \mathrm{a}$ & $12.1 \mathrm{a}$ \\
\hline Y2D2S1 & $16.85 a$ & $12.0 \mathrm{a}$ & $11.7 \mathrm{a}$ & $16.63 a$ & $11.6 \mathrm{a}$ & $11.0 \mathrm{a}$ \\
\hline Y2D2S2 & $16.76 \mathrm{a}$ & $12.0 \mathrm{a}$ & $12.6 \mathrm{a}$ & $10.97 \mathrm{~b}$ & $11.6 \mathrm{a}$ & $10.6 \mathrm{a}$ \\
\hline Y2D2S3 & $7.96 \mathrm{~b}$ & $12.0 \mathrm{a}$ & $11.4 \mathrm{a}$ & $7.28 c$ & $11.6 \mathrm{a}$ & $8.2 \mathrm{~b}$ \\
\hline Y2D3CK & $19.21 \mathrm{a}$ & $14.0 \mathrm{a}$ & $12.8 \mathrm{a}$ & $17.77 \mathrm{a}$ & $12.7 \mathrm{a}$ & $12.1 \mathrm{a}$ \\
\hline Y2D3S1 & $17.69 \mathrm{~b}$ & $14.0 \mathrm{a}$ & $10.7 \mathrm{a}$ & $14.98 \mathrm{~b}$ & $12.7 \mathrm{a}$ & $11.6 \mathrm{a}$ \\
\hline Y2D3S2 & $15.05 c$ & $14.0 \mathrm{a}$ & $10.8 \mathrm{a}$ & $10.12 \mathrm{c}$ & $12.7 \mathrm{a}$ & $9.5 \mathrm{~b}$ \\
\hline Y2D3S3 & $7.58 \mathrm{~d}$ & $14.0 \mathrm{a}$ & $10.2 \mathrm{a}$ & $5.40 d$ & $12.7 \mathrm{a}$ & $9.3 \mathrm{~b}$ \\
\hline Y2D5S3 & $4.70 c$ & $13.5 \mathrm{a}$ & $11.3 \mathrm{~b}$ & $4.40 \mathrm{~d}$ & $15.0 \mathrm{a}$ & $9.0 \mathrm{c}$ \\
\hline
\end{tabular}

Different lowercase letters indicate significant differences between treatments at $P<0.05$.

The 2017 yield data was published and cited in Yang et al. (2019).

ZD958, XY335 had better photosynthetic characteristics than did ZD958.

From silking to maturity, the LAD gradually decreased (Figure 4). Under CK, S1, S2, and S3, the LADs of XY335 were $44.3,43.6,40.6$, and $38.6 \mathrm{~m}^{2} /$ day, respectively, and they were $52.6,42.4,44.5,35.8$, and $33.7 \mathrm{~m}^{2} /$ day, under D1, D2, D3, D4, and D5, respectively (Figures $4 \mathrm{~A}-\mathrm{E}$ ). Under the CK, S1, S2, and S3, the LADs of ZD958 were $41.2,37.5,35.7$, and $30.5 \mathrm{~m}^{2} /$ day, respectively, and were $42.6,38.0,36.0,32.1$, and $32.5 \mathrm{~m}^{2}$ /day, under D1, D2, D3, D4, and D5, respectively (Figures $4 \mathbf{F}-\mathrm{J}$ ). As shown in Figure 4, LADs were greater for XY335 than for ZD958, as the LAD under $\mathrm{S} 1, \mathrm{~S} 2$, and S3 decreased significantly by 1.8 , 7.9, and $12.4 \%$, for XY335 and by 9.3, 13.6, and 24.6\% for ZD958. This indicated that LAD decreased as shading increased. Since the decrease rate of XY335 was lower than that of ZD958, XY335 had better leaves anti-aging ability than ZD958 (Figure 4).

\section{Relationships Between DMT and Accumulation and Leaf $P n, L A D$, and Their Correlations With the Yield}

DMT and AADMAS were significantly affected by both the $P n$ s and LAD (Figures 5A-D). First, leaf $P n$ and LAD were significantly negatively correlated with DMT and positively correlated with AADMAS, Specifically, when the $P n$ increased by $1 \mu \mathrm{mol} \mathrm{CO} 2 / \mathrm{m}^{2} / \mathrm{s}$. DMT decreased by $0.19 \mathrm{t} / \mathrm{ha}$ and AADMAS increased by $0.68 t /$ ha. Also, when the decreases in LAD increased 
TABLE 2 | Yield components of maize under different shading levels and planting densities.

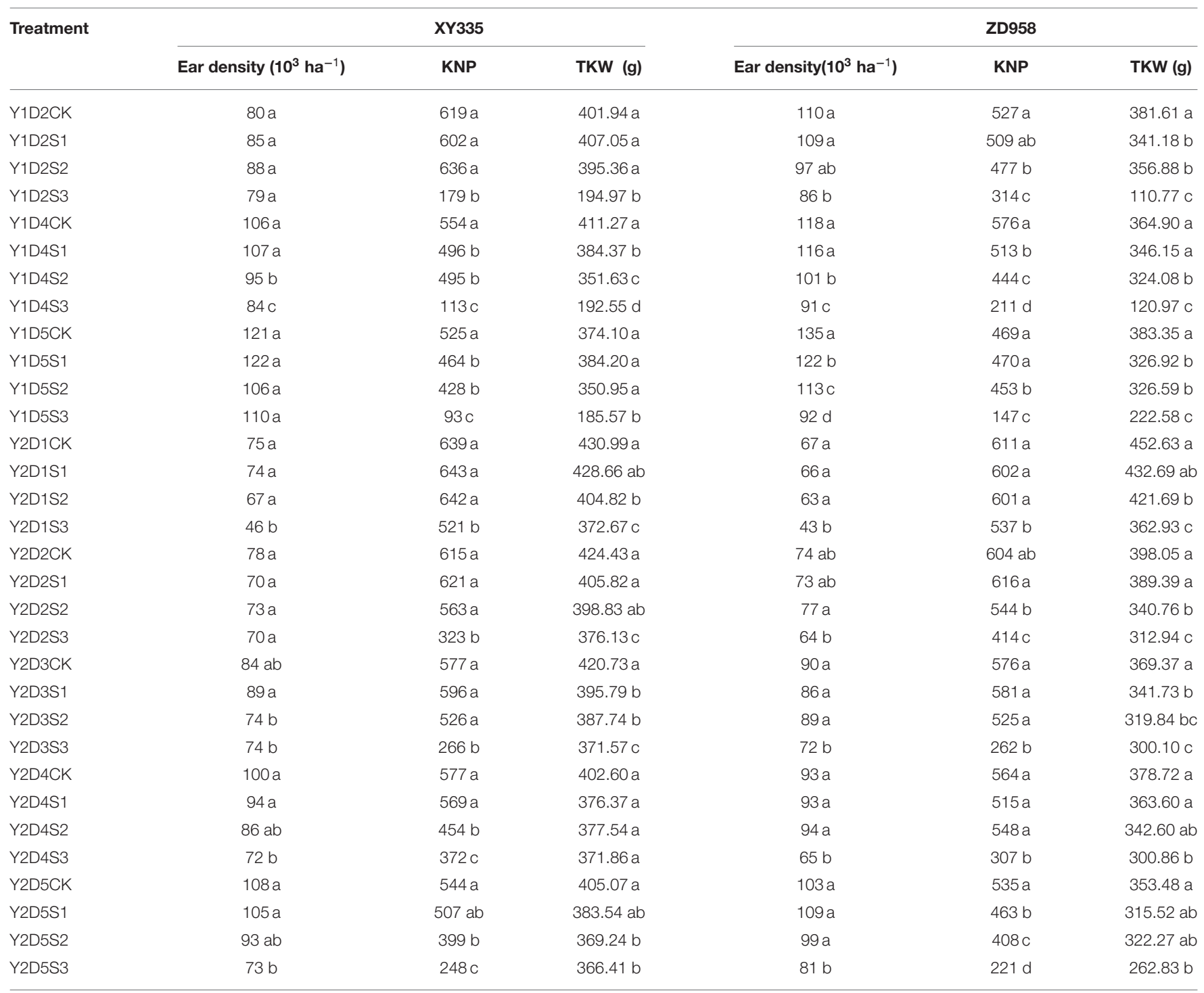

Different lowercase letters indicate significant differences between treatments at $P<0.05 . K N P$, kernel number per ear. TKW, thousand-kernel weight. See Table 1 for planting density and shading treatment definitions.

by $1 \mathrm{~m}^{2} /$ day, DMT decreased by $0.15 \mathrm{t} / \mathrm{ha}$ and AADMAS increased by $0.31 \mathrm{t} / \mathrm{ha}$.

As shown in Table 3, vegetative organ dry matter at silking (VS), at maturity (VM), ear density, and TKW were significantly affected by the interaction of $\mathrm{Y} \times \mathrm{C}$; VS, VM, and TKW were significantly affected by the interaction of $\mathrm{Y} \times \mathrm{D}$; yield, KNP, and TKW were significantly affected by the interaction of $Y \times$ $S$; VS, ear density, and TKW were significantly affected by the interaction of $\mathrm{C} \times \mathrm{D}$; yield, ear density, KNP, and TKW were significantly affected by the interaction of $\mathrm{C} \times \mathrm{S}$ and $\mathrm{D} \times \mathrm{S}(\mathrm{D}$ $\times \mathrm{S}$ was not significant for TKW); yield, VS, VM, ear density, KNP, and TKW were significantly affected by the interaction of $\mathrm{Y} \times \mathrm{C} \times \mathrm{D}$ and $\mathrm{Y} \times \mathrm{C} \times \mathrm{S}(\mathrm{Y} \times \mathrm{C} \times \mathrm{D}$ was not significant for yield and $\mathrm{Y} \times \mathrm{C} \times \mathrm{S}$ was not significant for VS); the interaction of $\mathrm{Y} \times \mathrm{D} \times \mathrm{S}$ was significant for TKW, the interaction of $\mathrm{C} \times \mathrm{D}$ $\times \mathrm{S}$ was significant for yield and KNP, and the interaction of $\mathrm{Y}$ $\times \mathrm{C} \times \mathrm{D} \times \mathrm{S}$ was significant for VM and TKW. VS and VM, as well as the AADMAS were significantly positively correlated with the yield (Figure 6). However, DMT was significantly negatively correlated with the yield.

\section{DISCUSSION}

As a primary environmental factor of crop growth, light intensity importantly influences maize yield (Jia et al., 2011; Shi et al., 2013; Ren et al., 2016; Hou et al., 2021). Indeed, we found that both dry matter weight and yield under our S1, S2, and S3 treatments were lower than those measures in CK, a result that has been found in other maize shading studies (Shi et al., 2015; Guo et al., 2020; Yang et al., 2021). Also, maize grain 

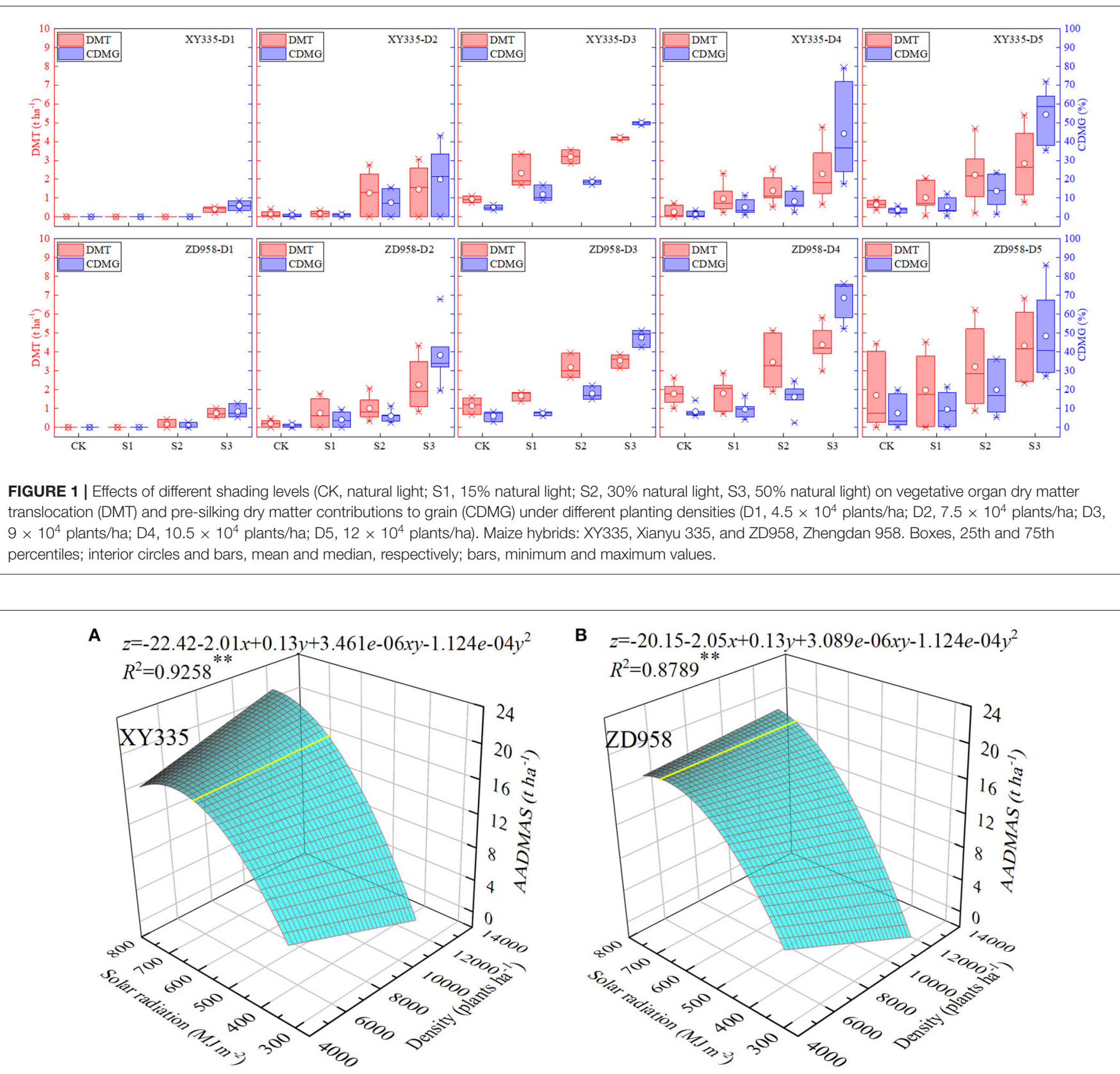

FIGURE 2 | Relationships between assimilation amount of dry matter after silking (AADMAS), planting density, and different totals of accumulated photosynthetically active radiation from the silking to the maturity stages in two maize hybrids (XY335 and ZD985). $x$ is planting density, $y$ is solar radiation, $z$ is AADMAS. ${ }^{* *} P \leq 0.01$.

yield is dependent on post-silking photosynthate accumulation and on the translocation of the reserved carbohydrates in vegetative organs (Barnabás et al., 2007; Wang et al., 2020a). We found that DMT and CDMG increased as shading levels increased and differed under different planting densities. Those results confirm those of Wang et al. (2020a) who reported that the translocation of pre-silking assimilates in vegetative organs increased under shading (Wang et al., 2020a). In our study, DMT increased as solar radiation decreased (Figure 1), and it was significantly negatively correlated with AADMAS and yield (Figure 6), thus suggesting that vegetative organ dry matter transportation to the grain could not compensate for the yield loss received by AADMAS under insufficient light environments. DMT and AADMAS reduction due to shading does not correspond to the magnitude of radiation reduction. The reason for this phenomenon may be that compensatory photosynthesis occurred under mild low-light conditions, while more photosynthates were used for respiration under severe lowlight conditions. Previous studies observed a similar result when grain dry matter that had been transferred from other organs was 

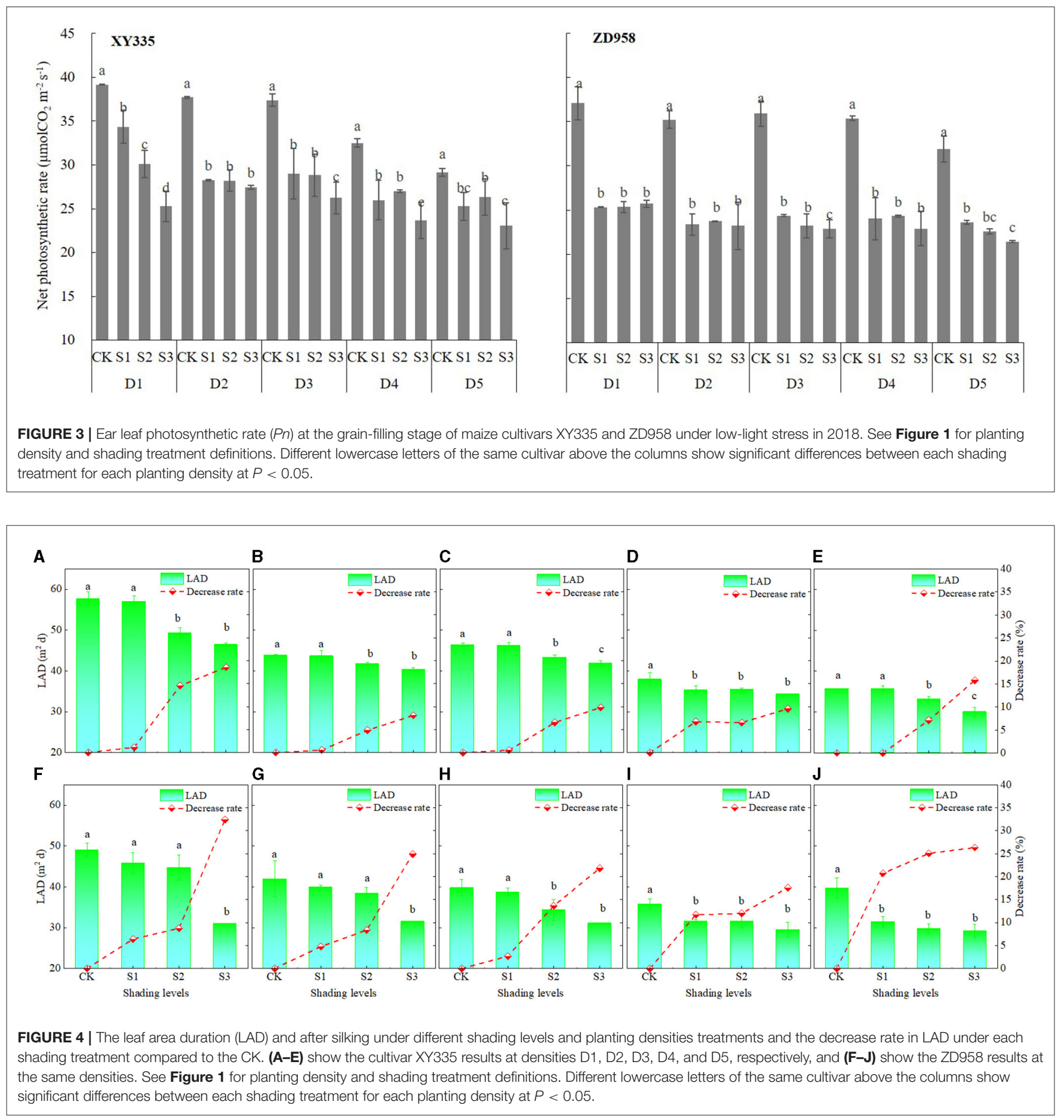

mainly from stems and leaves, but that amount was not large (Liang et al., 2015); and, during shading, it could not make up for the reduced post-silking biomass accumulation, thus resulting in lower yields (Mu et al., 2010; Wang et al., 2020a).

Modern maize grain yield improvement is highly dependent on increased plant density that intercepts more solar radiation than lower densities do (Antonietta et al., 2014; Liu et al., 2017; Hou et al., 2020). Previous studies have indicated that the ratio of transfer and contribution of dry matter in the stem increased when plant density increased, but that measure in leaves was the opposite (Han et al., 2008). Our results indicated that no such transfer occurred in CK, S1, and S2, whereas that transfer and contribution did occur in S3 planted at the lowest density (D1). This suggests that photosynthetic productivity after silking could supply yield formation demands and that transfer under low-density conditions is not needed. 

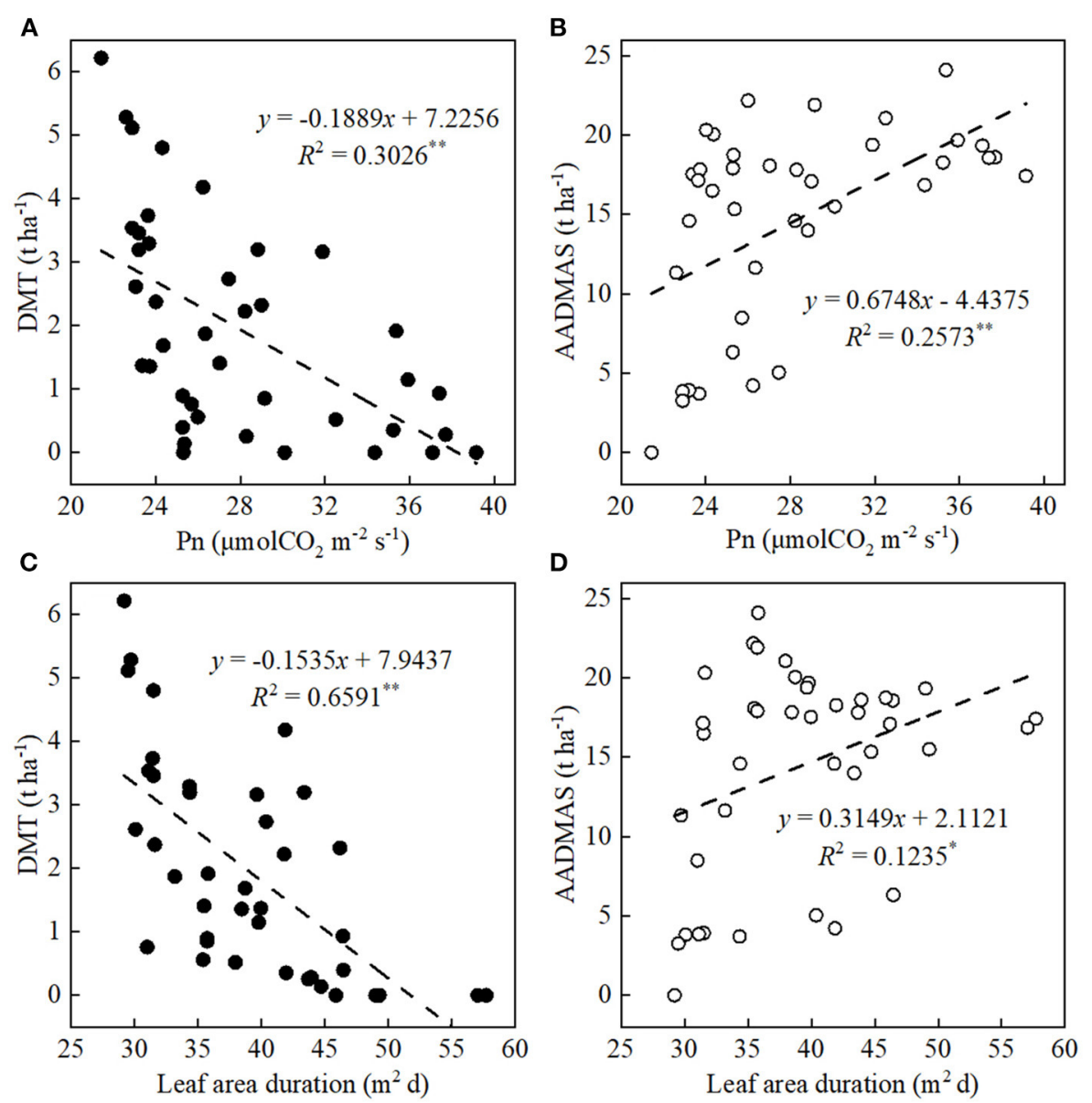

FIGURE 5 | Relationships between ear leaf photosynthetic rates $(P n)$ at the grain-filling stage and LAD with DMT and AADMAS. DMT and AADMAS are indicated by solid circles and empty circles, respectively. ${ }^{\star} P \leq 0.05,{ }^{\star \star} P<0.01$.

TABLE 3 | ANOVA analysis for the effects of year, cultivar, planting density and shading level on the grain yields, yield components (KNP, kernel number per ear. TKW, thousand-kernel weight) and dry weights of plant organs (dry matter of vegetative organs at silking [VS] and at maturity [VM]).

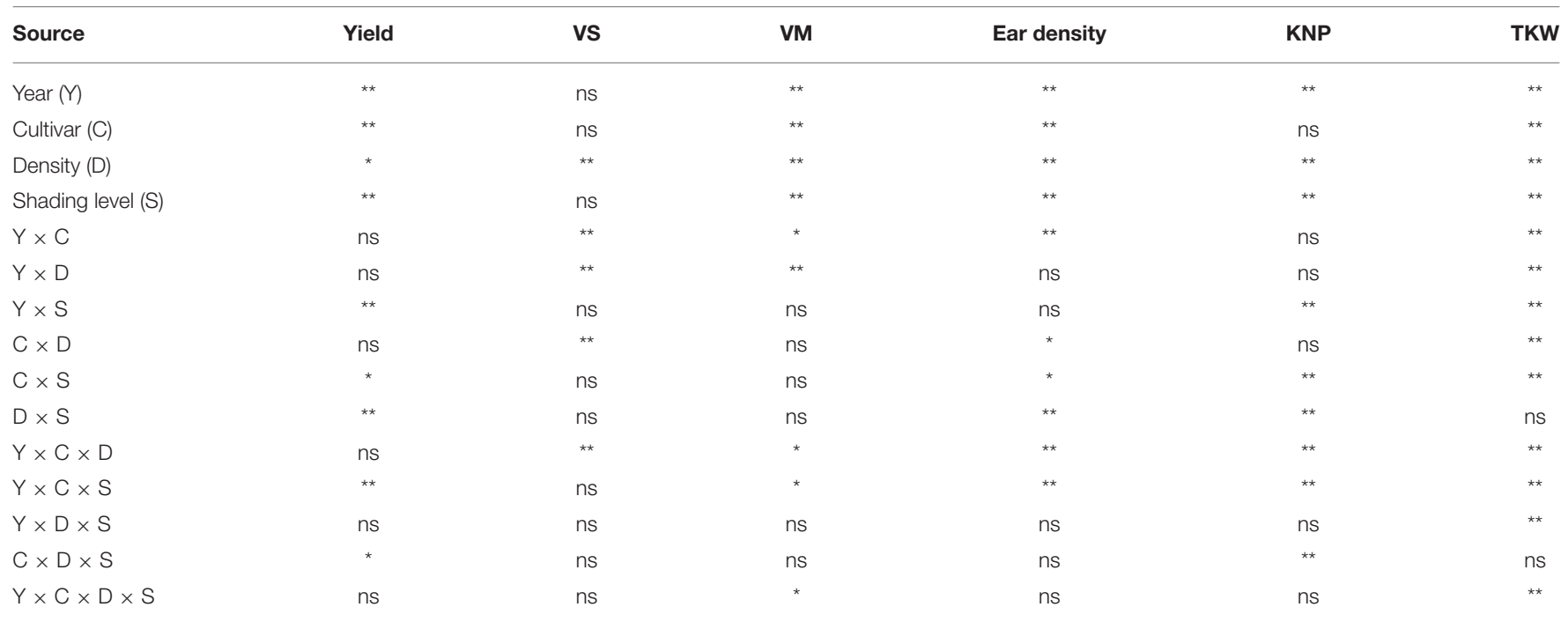

${ }^{*}$ and ${ }^{* *}$ indicate significant differences at $P<0.05$ and $P<0.01$ probability levels, $n$ s indicates no significance, respectively. 


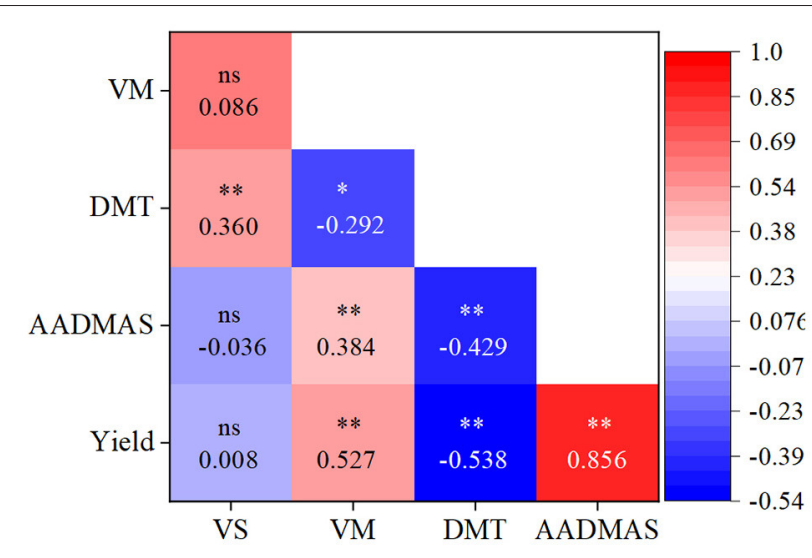

FIGURE 6 | Relationships of yield, vegetative organ dry matter at silking (VS) and at maturity (VM), and AADMAS and DMT, across all treatments, including different shading levels, cultivars, and planting densities. ${ }^{\star} P<0.05$; ${ }^{\star \star} P<0.01$; ns, not significant.

Furthermore, as density increased, transfer occurred in the shading treatments. Also, the higher the planting density the greater transfer need, thus indicating that the photosynthate produced under high density and weak light could not satisfy yield formation (Figure 1). In support of several studies (Cui et al., 2013a; Liu et al., 2021b), our results suggest that solar radiation intensity is the limiting factor for AADMAS, and that given sufficient light radiation, increased planting density fosters increased AADMAS and thus effectively increases yield (Yang et al., 2019) (Figure 2).

Photosynthesis, the main physiological process that drives plant growth, is very sensitive to light changes (Fan et al., 2018; Wu et al., 2020). Dry-matter production, especially post-silking dry matter accumulation, is closely related to photosynthetic capacity (Liu et al., 2020a). As the main photosynthetic organs, leaves (Chen, 1994; Ye et al., 2020) provide assimilates for grain development and directly affect the final yield (Tollenaar and Daynard, 1982; Barnabás et al., 2007; Zhang et al., 2007; Mu et al., 2010). Previous studies have shown that since shading likely hinders leaf photoprotective mechanisms and chlorophyll fluorescence properties, the result is decreased net photosynthetic capacity (Cui et al., 2013b; Gao et al., 2017). Decreased photosynthetic capacity was likely due to leaf senescence (Ye et al., 2020). We found that, for the physiological traits, the LAD decreased as shading increased (Figure 4), and that was accompanied by a decreasing net $P n$, likely a consequence of leaf senescence. Based on previous research (Qian et al., 2021), the translocation of reserved carbohydrates in vegetative organs to grains was one of the important factors that determined maize yield. If the transport exceeded $20 \%$, it would cause early senescence of maize leaves (Qian et al., 2021). However, in the present study, the average transport (CDMG) of both tested cultivars was 15.4\% (Figure 1). As shown in Figures 5 and 6, LAD was significantly negatively correlated with DMT and positively correlated with AADMAS. It meant that in the shortage of light resources condition, the sink required more transport of nutrients from the vegetative organs which would deprive the strength of leaf photosynthetic capacity and affect the production of dry matter. This might be one reason for early senescence of leaves under low light conditions in this study. On the other hand, the main resource for grain yield was still from photosynthetic products formed after silking.

Differences in yield and photosynthate accumulation and translocation under light intensity changes vary among maize cultivars (Liang et al., 2015; Wang et al., 2020a). In comparing those differences in cultivars XY335 and ZD958, we found that the average yield of XY335 was higher than that of ZD958. The sink characters of KNP and TKW of XY335 were higher than that of ZD958, and DMT and CDMG rates increased more for XY335 than for ZD958, thus indicating that XY335 transferred more photosynthetic products to grain than ZD958. This indicated that the sink capacity of XY335 was better than that of ZD958 under low-solar radiation stress, and that may promote increased DMT in XY335 (Borrás et al., 2004). Also, the photosynthetic substances produced by ZD958 were used mostly for vegetative organ growth. Comparing the results of the quantitative relationship of the two cultivars (Figure 2), the corresponding demarcation value for XY335 was smaller than that for ZD958, which indicated that XY335 had better resistance than ZD958 to weak light. Additionally, under light stress, the range of $P n$ decrease in XY335was lower than that in ZD958, and the LAD decreased rate of ZD958was faster than that of XY335. XY335 has a greater leaf source duration and dry matter production capacity than ZD958. Hou et al. (2020) reported that XY335 had a compact canopy and became more compact at the high density. Other studies showed that the optimal spatial distribution of leaves contributed to delayed leaf senescence and intercept more solar radiation to improve the photosynthetic rate and promote the production potentials of maize at high planting density (Bai et al., 2020; Liu et al., 2021a). However, Antonietta et al. (2014) reported that delayed leaf senescence did not increase yields under high planting density, this may be due to different maize hybrids. So, in this study, XY335 was better able to adapt to weak light, have anti-aging ability, and maintain a higher photosynthetic ability compared to ZD958. Consequently, those superior low-light abilities may lower yield loss caused by light deficiency (Wang et al., 2020b; Wu et al., 2020).

\section{CONCLUSIONS}

This study of maize cultivars XY335 and ZD958 determined the differences in DMT contributions under different shading levels and planting densities, and the quantitative relationship between solar radiation, density, and the accumulation of dry matter. In conclusion, shading significantly reduced the $P n$ and LAD, which consequently reduced the amount of dry matter assimilated and thus lowered maize yield. Maize hybrid XY335 was better able to adapt to weak light, maintain a higher photosynthetic and antiaging ability compared with the cultivar ZD958. These findings show the importance of selecting maize cultivars that have strong stay-green abilities that can guarantee good grain yields even under weak light conditions. 


\section{DATA AVAILABILITY STATEMENT}

The original contributions presented in the study are included in the article/supplementary material, further inquiries can be directed to the corresponding authors.

\section{AUTHOR CONTRIBUTIONS}

YY, PH, and SL designed the study. YY, XG, GL, and WL performed the study. YY, XG, GL, WL, JX, BM, RX, KW, PH, and SL analyzed data and performed the statistical analyses. YY wrote

\section{REFERENCES}

Andrade, F. H., and Ferreiro, M. A. (1996). Reproductive growth of maize, sunflower and soybean at different source levels during grain filling. Field Crop. Res. 48, 155-165. doi: 10.1016/S0378-4290(96)01017-9

Andrade, F. H., Otegui, M. E., and Vega, C. (2000). Intercepted radiation at flowering and kernel number in maize. Semigroup Forum 92, 92-97. doi: 10.2134/agronj2000.92192x

Andrade, F. H., Uhart, S. A., and Frugone, M. I. (1993). Intercepted radiation at flowering and kernel number in maize: shade versus plant density effects. Crop Sci. 33, 482-485. doi: 10.2135/cropsci1993.0011183X003300030013x

Antonietta, M., Fanello, D. D., Acciaresi, H. A., and Guiamet, J. J. (2014). Senescence and yield responses to plant density in stay green and earliersenescing maize hybrids from Argentina. Field Crop. Res. 155, 111-119. doi: 10.1016/j.fcr.2013.09.016

Bai, Y. W., Zhang, H., Zhu, Y. L., Zheng, X. H., Yang, M., Li, C. F., et al. (2020). Responses of canopy radiation and nitrogen distribution, leaf senescence and radiation use efficiency on increased planting density of different variety types of maize. Scientia Agric. Sin. 53, 3059-3070. doi: 10.3864/j.issn.0578-1752.2020.15.007

Balwinder, S., Shirsath, P. B., Jat, M. L., McDonald, A. J., Srivastava, A. K., et al. (2020). Agricultural labor, COVID-19, and potential implications for food security and air quality in the breadbasket of India. Agric. Syst. 185:102954. doi: 10.1016/j.agsy.2020.102954

Barnabás, B., Jäger, K., and Fehér, A. (2007). The effect of drought and heat stress on reproductive processes in cereals. Plant Cell Environ. 31, 11-38. doi: 10.1111/j.1365-3040.2007.01727.x

Borrás, L., Slafer, G. A., and Otegui, M. E. (2004). Seed dry weight response to source-sink manipulations in wheat, maize and soybean: a quantitative reappraisal. Field Crop. Res. 86, 131-146. doi: 10.1016/j.fcr.2003.08.002

Cerrudo, A., Di Matteo, J., Fernandez, E., Robles, M., Olmedo Pico, L., and Andrade, F. H. (2013). Yield components of maize as affected by short shading periods and thinning. Crop Pasture Sci. 64, 580-587. doi: 10.1071/CP 13201

Chen, G. P. (1994). The production and distribution of dry matter in maize. J. Maize Sci. 2, 48-53.

Cui, H. Y., Camberato, J. J., Jin, L. B., and Zhang, J. W. (2015). Effects of shading on spike differentiation and grain yield formation of summer maize in the field. Int. J. Biometeorol. 59, 1189-1200. doi: 10.1007/s00484-014-0930-5

Cui, H. Y., Jin, L. B., Li, B., Zhang, J. W., Zhao, B., Dong, S. T., et al. (2012). Effects of shading on stalks morphology, structure and lodging of summer maize in field. Sci. Agric. Sinica 45, 3497-3505. doi: 10.3864/j.issn.0578-1752.2012.17.005

Cui, H. Y., Jin, L. B., Li, B., Zhao, B., Dong, S. T., Liu, P., et al. (2013b). Effects of shading on photosynthetic characteristics and xanthophyll cycle of summer maize in the field. Acta Agron. Sin. 39, 478-485. doi: 10.3724/SP.J.1006.2013.00478

Cui, H. Y., Jin, L. B., Li, B., Dong, S. T., Liu, P., Zhao, B., et al. (2013a). Effects of shading on dry matter accumulation and nutrient absorption of summer maize. Chin. J. Appl. Ecol. 24, 3099-3105. doi: 10.13287/j.1001-9332.2013.0533

Ding, L., Wang, K. J., Jiang, G. M., Liu, M. Z., and Gao, L. M. (2005). Post-anthesis changes in photosynthetic traits of maize hybrids released in different years. Field Crop. Res. 93, 108-115. doi: 10.1016/j.fcr.2004.09.008 the paper. All authors contributed to the article and approved the submitted version.

\section{ACKNOWLEDGMENTS}

We thank the National Key Research and Development Program of China (2017YFD0300303, 2016YFD0300110, and 2016YFD0300101), the National Natural Science Foundation of China (31871558 and 31501266), the National Basic Research Program of China (973, Program: 2015CB150401), and the China Agriculture Research System of MOF and MARA.

Dordas, C. (2009). Dry matter, nitrogen and phosphorus accumulation, partitioning and remobilization as affected by $\mathrm{N}$ and $\mathrm{P}$ fertilization and sourcesink relations. Eur. J. Agron. 30, 129-139. doi: 10.1016/j.eja.2008.09.001

Early, E. B., Mcllrath, W. O., Seif, R. D., and Hageman, R. H. (1967). Effects of shade applied at different stages of plant development on corn (Zea mays L.) production. Crop Sci. 7, 151-156. doi: 10.2135/cropsci1967.0011183X000700020018x

Fan, Y. F., Chen, J. X., Cheng, Y. J., Raza, M. A., Wu, X. L., Wan, Z. L., et al. (2018). Effect of shading and light recovery on the growth, leaf structure, and photosynthetic performance of soybean in a maize-soybean relay-strip intercropping system. PLoS ONE 13, 1-15. doi: 10.1371/journal.pone.0198159

Gao, J., Zhao, B., Dong, S. T., Liu, P., Ren, B. C., and Zhang, J. W. (2017). Response of summer maize photosynthate accumulation and distribution to shading stress assessed by using ${ }^{13} \mathrm{CO}_{2}$ stable isotope tracer in the field. Front. Plant Sci. 8, 1-12. doi: 10.3389/fpls.2017.01821

Guo, X. X., Yang, Y. S., Liu, H. F., Liu, G. Z., Liu, W. M., Wang, Y. H., et al. (2020). Effects of solar radiation on root and shoot growth of maize and the quantitative relationship between them. Crop Sci. 61, 1414-1425. doi: 10.1002/csc2.20416

Han, J. L., Li, Y. S., Yang, Q., Zhou, Y. F., Wang, W. P., 1,I, Q. S., et al. (2008). The effect of plant density on regularity of accumulation, aistribution and transfer of dry matter on spring maize. J. Maize Sci. 16, 115-119. doi: 10.13597/j.cnki.maize.science.2008.05.034

Hou, P., Gao, Q., Xie, R., Li, S., Meng, Q., Kirkby, E. A., et al. (2012). Grain yields in relation to $\mathrm{N}$ requirement: Optimizing nitrogen management for spring maize grown in China. Field Crop. Res. 129, 1-6. doi: 10.1016/j.fcr.2012.01.006

Hou, P., Liu, Y. E., Liu, W. M., Liu, G. Z., Xie, R. Z., Wang, K. R., et al. (2020). How to increase maize production without extra nitrogen input. Resour. Conserv. Recyl. 160:104913. doi: 10.1016/j.resconrec.2020.104913

Hou, P., Liu, Y. E., Liu, W. M., Yang, H. S., Xie, R. Z., Wang, K. R., et al. (2021). Quantifying maize grain yield losses caused by climate change based on extensive field data across China. Resour. Conserv. Recyl. 174:105811. doi: 10.1016/j.resconrec.2021.105811

Ibrahim, M. A. S., Ahmed, K. E., Osman, S., Ali, E. T., and Hamada, A. A. (2010) Response of new cotton varieties to nitrogen fertilization in Sudan Gezira. Afr. J. Agric. Res. 5, 1213-1219. doi: 10.1021/jf1009318

Jia, S. F., Dong, S. T., Wang,. K. J., Zhang,. J. W., and Feng, L. C. (2007). Effect of shading on grain quality at different stages of corn flowering. Acta Agron. Sin. 12, 1960-1967. doi: 10.3321/j.issn:0496-3490.2007.12.007

Jia, S. F., Li, C. F., Dong, S. T., and Zhang, J. W. (2011). Effects of shading at different stages after anthesis on maize grain weight and quality at cytology level. Agric. Sci. China 10, 58-69. doi: 10.1016/S1671-2927(11)60307-6

Jin, W. Q., Urbina, J. L., Heuvelink, E., Marcelis, and Leo, F. M. (2020). Adding farred to red-blue light-emitting diode light promotes yield of lettuce at different planting densities. Front, Plant Sci. 11:609977. doi: 10.3389/fpls.2020.609977

Karlen, D. L., Sadler, E. J., and Camp, C. R. (1987). Dry matter, nitrogen, phosphorus, and potassium accumulation rates by corn on norfolk loamy sand1. Agron. J. 79, 649-656. doi: 10.2134/agronj1987.000219620079000 $40014 x$

Lamichhane, J. R., and Reay-Jones, F. P. (2021). Editorial: Impacts of COVID19 on global plant health and crop protection and the resulting effect on global food security and safety. Crop Prot. 139, 1-3. doi: 10.1016/j.cropro.2020. 105383 
Liang, X. T., Lu, Z. Y., and Li, W. Y. (2015). Effect of different row spacing on dynamic of dry matter accumulation and distribution. J. Maize Sci. 23, 110-116. doi: $10.13597 / j . c n k i . m a i z e . s c i e n c e .20150420$

Liu, G. Z., Hou, P., Xie, R. Z., Ming, B., Wang, K. R., and Liu, W. M. (2019). Nitrogen uptake and response to radiation distribution in the canopy of high-yield maize. Crop Sci. 59, 1236-1247. doi: 10.2135/cropsci2018.09.0567

Liu, G. Z., Hou, P., Xie, R. Z., Ming, B., Wang, K. R., Xu, W. J., et al. (2017). Canopy characteristics of high-yield maize with yield potential of $22.5 \mathrm{Mg} \mathrm{ha}^{-1}$. Field Crop. Res. 213, 221-230. doi: 10.1016/j.fcr.2017.08.011

Liu, G. Z., Liu, W. M., Hou, P., Ming, B., Yang, Y. S., Guo, X. X., et al. (2021b). Reducing maize yield gap by matching plant density and solar radiation. J. Integr. Agric. 20, 363-370. doi: 10.1016/S2095-3119(20)63363-9

Liu, G. Z., Yang, H. S., Xie, R. Z., Yang, Y. S., Liu, W. M., Guo, X. X., et al. (2021a). Genetic gains in maize yield and related traits for high-yielding cultivars released during 1980s to 2010s in China. Field Crop. Res. 270:108223. doi: 10.1016/j.fcr.2021.108223

Liu, G. Z., Yang, Y. S., Liu, W. M., Guo, X. X., Xue, J., Xie, R. Z., et al. (2020a). Leaf removal affects maize morphology and grain yield. Agron. 10, 1-12. doi: 10.3390/agronomy10020269

Liu, T. N., Gu, L. M., Dong, S. T., Zhang, J. W., Liu, P., and Zhao, B. (2015). Optimum leaf removal increases canopy apparent photosynthesis, ${ }^{13} \mathrm{C}$ photosynthate distribution and grain yield of maize crops grown at high density. Field Crop. Res. 170, 32-39. doi: 10.1016/j.fcr.2014.09.015

Liu, W., Zhang, J. W., Lv, P., Yang, J. S., Liu, P., Dong, S. T., et al. (2011). Effect of plant density on grain yield dry matter accumulation and partitioning in summer maize cultivar denghai 661. Acta Agron. Sin. 37, 1301-1307. doi: 10.3724/SP.J.1006.2011.01301

Liu, W. M., Hou, P., Liu, G. Z., Yang, Y. S., Guo, X. X., Ming, B., et al. (2020b). Contribution of total dry matter and harvest index to maize grain yield-A multisource data analysis. Food Energy Secur. 9, 1-12. doi: 10.1002/fes3.256

Liu, Y. E., Li, Y. X., Lv, T. F., Xing, J. F., Xu, T. J., Cai, W. T., et al. (2021c). The priority of management factors for reducing the yield gap of summer maize in the north of Huang-Huai-Hai region, China. J. Integrat. Agric. 20, 450-459. doi: 10.1016/S2095-3119(20)63294-4

Ma, D. L., Xie, R. Z., Niu, X. K., Li, S. K., Long, H. L., and Liu, Y. E. (2014). Changes in the morphological traits of maize genotypes in China between the 1950s and 2000s. Eur. J. Agron. 58, 1-10. doi: 10.1016/j.eja.2014. 04.001

Ma, D. Y., Guo, T. C., Wang, C. Y., Zhu, Y. J., Song, X., Wang, Y. H., et al. (2008). Effects of nitrogen application rates on accumlation, translocation, and partitioning of photosynthate in winter wheat at grain filling stage. Acta Agron. Sin. 34, 1027-1033. doi: 10.3724/SP.J.1006.2008.01027

Mu, H., Jiang, D., Wollenweber, B., Dai, T., Jing, Q., and Cao, W. (2010). Long-term low radiation decreases leaf photosynthesis, photochemical efficiency and grain yield in winter wheat. J. Agron. Crop Sci. 196, 38-47. doi: 10.1111/j.1439-037X.2009.00394.x

Pu, T., Zhang, Q., Cheng, G. P., Zeng, H., Peng, X., Yang, W. Y., et al. (2016). Effects of row spacing on yield, dry matter accumulation and partitioning of maize in maizesoybean relay strip intercropping system. Acta Agric. Zhejiangensis 28, 1277-1286. doi: 10.3969/j.issn.1004-1524.2016.08.02

Qian, C. R., Wang, R. H., Yu, Y., Xu, T. J., Gong, X. J., Hao, Y. B., et al. (2021). Characteristics of dry matter accumulation, transportation and distribution of maize varieties differing in maturities in different ecological zones. J. Maize Sci. 29, 60-68. doi: 10.13597/j.cnki.maize.science.20210210

Ren, B. Z., Cui, H. Y., Camberato, J. J., Dong, S. T., Liu, P., Zhao, B., et al. (2016). Effects of shading on the photosynthetic characteristics and mesophyll cell ultrastructure of summer maize. Sci. Nat. 103:67. doi: 10.1007/s00114-016-1392-x

Shi, J. G., Zhu, K. L., Cao, H. Y., Dong, S. T., Liu, P., Zhao, B., et al. (2015). Effect of light from flowering to maturity stage on dry matter accumulation and nutrient absorption of summer maize. Chin. J. Appl. Ecol. 26, 46-52. doi: $10.13287 /$ j.1001-9332.20141029.013

Shi, J. G., Cui, H. Y., Zhao, B., Dong, S. T., Liu, P., and Zhang, J. W. (2013). Effect of light on yield and characteristics of grain-filling of summer maize from flowering to maturity. Sci. Agric. Sin. 46, 4427-4434. doi: 10.3864/j.issn.0578-1752.2013.21.004

Srinivasan, V., Kumar, P., and Long, S. P. (2017). Decreasing, not increasing, leaf area will raise crop yields under global atmospheric change. Global Change Biol. 23, 1626-1635. doi: $10.1111 / \mathrm{gcb} .13526$
Tollenaar, M., and Daynard, T. B. (1982). Effect of source-sink rayion on dry matter accumulation and leaf senesece of maize. Plant Sci.62, 855-860. doi: $10.4141 /$ cjps $82-128$

Wang, J., Shi, K., Lu, W. P., and Lu, D. L. (2020a). Post-silking shading stress affects leaf nitrogen metabolism of spring maize in southern China. Plants 9, 1-15. doi: $10.3390 /$ plants 9020210

Wang, Y., Zhang, Z. K., Liang, Y. Y., Han, Y. L., Han, Y. L., and Tan, J. F. (2020b). High potassium application rate Increased grain yield of shading-stressed winter wheat by improving photosynthesis and photosynthate translocation. Front. Plant Sci. 11, 1-10. doi: 10.3389/fpls.2020.00134

Wei, S. S., Wang, X. Y., Li, G. H., Jiang, D., and Dong, S. T. (2019). Maize canopy apparent photosynthesis and ${ }^{13} \mathrm{C}$-photosynthate reallocation in response to different density and $\mathrm{N}$ rate combinations. Front. Plant Sci. 10:1113. doi: $10.3389 /$ fpls.2019.01113

Wu, H. Y., Tang, H. K., Liu, L. A., Shi, L., Zhang, W. F., and Jiang, C. D. (2020). Local weak light induces the improvement of photosynthesis in adjacent illuminated leaves in maize seedlings. Physiol. Plant 2020, 1-12. doi: $10.1111 /$ ppl.13220

Xu, W. J., Liu, C. W., Wang, K. R., Xie, R. Z., Ming, B., Wang, Y. H., et al. (2017). Adjusting maize plant density to different climatic conditions across a large longitudinal distance in China. Field Crop. Res. 212, 126-134. doi: 10.1016/j.fcr.2017.05.006

Xue, J., Gou, L., Zhao, Y. S., Yao, M. N., Yao, H. H., Tian, J. S., et al. (2016). Effects of light intensity within the canopy on maize lodging. Field Crop. Res. 188, 133-141. doi: 10.1016/j.fcr.2016.01.003

Yan, J. M., Zhai, H. Q., Zhang, R. X., Jiao, D. M., Chen, B. S., and Zhang, H. S., (2001). Studies on characteristics of photosynthesis and assimilate's transportation in heavy Ear hybrid rice (Oryza sativa L. ). Acta Agron. Sin. 27, 261-266. doi: 10.3321/j.issn:0496-3490.2001.02.020

Yang, J., Zhu, Q., Wang, Z., and Lang, Y. (1997). Photosynthetic characteristics, dry matter accumulation and its translocation in intersubspecific hybrid rice. Acta Agron. Sin. 23, 82-88.

Yang, Y. S., Guo, X. X., Hou, P., Xue, J., Liu, G. Z., Liu, W., et al. (2020). Quantitative effects of solar radiation on maize lodging resistance mechanical properties. Field Crop. Res. 255:7906. doi: 10.1016/j.fcr.2020. 107906

Yang, Y. S., Guo, X. X., Liu, H. F., Liu, G. Z., Liu, W. M., Ming, B., et al. (2021). The effect of solar radiation change on the maize yield gap from the perspectives of dry matter accumulation and distribution. J. Integr. Agric. 20, 482-493. doi: 10.1016/S2095-3119(20)63581-X

Yang, Y. S., Xu, W. J., Hou, P., Liu, G. Z., Liu, W. M., Wang, Y. H., et al. (2019). Improving maize grain yield by matching maize growth and solar radiation. Sci. Rep. 9, 1-11. doi: 10.1038/s41598-019-40081-z

Yang, H. J., Li, Y. Z., Huang, Y. M., Zheng, J. S., Jiang, Z. W., and Lin, W. (1999). Yield components and structures of sink source in super high yielding rice. Fujian J. Agric. Sci. 1, 1-5. doi: 10.19303/j.issn.1008-0384.1999.01.001

Ye, Y. X., Wen, Z. R., Yang, H., Lu, W. P., and Lu, D. L. (2020). Effects of post-silking water deficit on the leaf photosynthesis and senescence of waxy maize. J. Integr. Agric. 19, 2216-2228. doi: 10.1016/S2095-3119(20) 63158-6

Zhang, G. Q., Liu, C. W., Xiao, C. H., Xie, R. Z., Ming, B., Hou, P., et al. (2017). Optimizing water use efficiency and economic return of super high yield spring maize under drip irrigation and plastic mulching in arid areas of China. Field Crop. Res. 211, 137-146. doi: 10.1016/j.fcr.2017.05.026

Zhang, J. W., Dong, S. T., Wang, K. J., Hu, C. H., and Liu, P. (2006). Effects of shading on the growth,development and grain yield of summer maize. Chin. J. Appl. Ecol. 17, 657. doi: 10.13287/j.1001-9332.2006.0133

Zhang, F. J., Gao, J. L., Xu, Z. Q., and Hu, S. P. (2016). The effects of sourcesink characteristics on yield of super-high-yield spring corn. J. Northern Agric. 44, 1-6. doi: 10.3969/j.issn.2096-1197.2016.01.01

Zhang, J. W., Dong, S. T., Wang, K. J., Hu, C. H., and Liu, P. (2007). Effects of shading in field on photosynthetic characteristics in summer corn. Acta Agron. Sin. 33, 216-222. doi: 10.13287/j.1001-9332.2007.0409

Zhou, L., Wang, Z. H., Li, F. C., Meng, X. Y., and Li, S. X. (2012). Analysis of dry matter accumulation and translocation for winter wheat cultivars with different yields on dryland. Acta Ecol. Sin. 32, 4123-4131. doi: 10.5846/stxb201106120775

Zhu, M., Ge, Y. X., Li, F. H., Wang, Z. B., Wang, H. W., and Shi, Z. S. (2011). Accumulation and translocation of dry matter and nitrogen in 
different purple corn hybrids (Zea mays L.). Afr. J. Agric. Res. 6, 2820-2827. doi: 10.5897/AJAR10.1164

Conflict of Interest: The authors declare that the research was conducted in the absence of any commercial or financial relationships that could be construed as a potential conflict of interest.

Publisher's Note: All claims expressed in this article are solely those of the authors and do not necessarily represent those of their affiliated organizations, or those of the publisher, the editors and the reviewers. Any product that may be evaluated in this article, or claim that may be made by its manufacturer, is not guaranteed or endorsed by the publisher.

Copyright $\odot 2021$ Yang, Guo, Liu, Liu, Xue, Ming, Xie, Wang, Hou and Li. This is an open-access article distributed under the terms of the Creative Commons Attribution License (CC BY). The use, distribution or reproduction in other forums is permitted, provided the original author(s) and the copyright owner(s) are credited and that the original publication in this journal is cited, in accordance with accepted academic practice. No use, distribution or reproduction is permitted which does not comply with these terms. 